\title{
Susceptibility of Enamel to Initial Erosion in Relation to Tooth Type, Tooth Surface and Enamel Depth
}

\author{
Thiago S. Carvalho A. Lussi \\ Department of Preventive, Restorative and Pediatric Dentistry, University of Bern, Bern, Switzerland
}

\section{Key Words}

Dental erosion - Enamel $\cdot$ Knoop hardness - Calcium release

\begin{abstract}
This study aimed at assessing the susceptibility of different tooth types (molar/premolar), surfaces (buccal/lingual) and enamel depths $(100,200,400$ and $600 \mu \mathrm{m})$ to initial erosion measured by surface microhardness loss $(\triangle \mathrm{SMH})$ and calcium (Ca) release. Twenty molars and 20 premolars were divided into experimental and control groups, cut into lingual/ buccal halves, and ground/polished, removing $100 \mu \mathrm{m}$ of enamel. The initial surface microhardness $\left(\mathrm{SMH}_{0}\right)$ was measured on all halves. The experimental group was subjected to 3 consecutive erosive challenges $(30 \mathrm{ml} /$ tooth of $1 \%$ citric acid, $\left.\mathrm{pH} 3.6,25^{\circ} \mathrm{C}, 1 \mathrm{~min}\right)$. After each challenge, $\Delta \mathrm{SMH}$ and $\mathrm{Ca}$ release were measured. The same teeth were consecutively ground to 200,400 and $600 \mu \mathrm{m}$ depths, and the experimental group underwent 3 erosive challenges at each depth. No difference was found in $\mathrm{SMH}_{0}$ between experimental and control groups. Multivariate nonparametric ANOVA showed no significant differences between lingual and buccal surfaces in $\triangle S M H(p=0.801)$ or Ca release $(p=$ 0.370 ). $\triangle S M H$ was significantly greater in premolars than in molars ( $p<0.05)$, but not different with respect to enamel depth. Ca release decreased significantly with increasing depth. Regression between Ca release and $\Delta \mathrm{SMH}$ at $100 \mu \mathrm{m}$ depth showed lower slope and $r^{2}$ value, associated with greater Ca release values. At 200-600 $\mu \mathrm{m}$ depths, moder-
\end{abstract}

\begin{tabular}{ll}
\hline KARGER 125/s & $\begin{array}{l}\text { ( } 2015 \text { S. Karger AG, Basel } \\
0008-6568 / 15 / 0492-0109 \$ 39.50 / 0\end{array}$ \\
$\begin{array}{l}\text { E-Mail karger@karger.com } \\
\text { www.karger.com/cre }\end{array}$ & $\begin{array}{l}\text { This is an Open Access article licensed under the terms of the } \\
\text { Creative Commons Attribution-NonCommercial 3.0 Un- } \\
\text { ported license (CC BY-NC) (www.karger.com/OA-license), } \\
\text { applicable to the online version of the article only. Distribu- } \\
\text { tion permitted for non-commercial purposes only. }\end{array}$
\end{tabular}

ately large $r^{2}$ values were observed (0.651-0.830). In conclusion, different teeth and enamel depths have different susceptibility to erosion, so when Ca release is used to measure erosion, the depth of the test facet in enamel should be standardized, whereas this is less important if $\triangle S M H$ is used.

(c) 2015 S. Karger AG, Basel

\section{Introduction}

Dental enamel is made up of bundles of parallel hydroxyapatite crystals, which form rod-shaped structures extending from the dentino-enamel junction (DEJ) to the outer surface of the tooth [Daculsi et al., 1984]. Histologically, the mineral composition of enamel can differ depending on the individual, the tooth anatomy, the tooth surface and even on the specific location on the tooth [Weatherell et al., 1974]. The mineral content and, correspondingly, the calcium concentration and density of enamel decrease toward the DEJ [Robinson et al., 1971], but the concentrations of carbonate and magnesium increase [Weatherell et al., 1968]. Fluoride concentrations are considerably higher in the outermost layer of enamel [Hallsworth and Weatherell, 1969]. These gradients have been used to explain the increase in mineral solubility occurring in enamel, from the surface to the DEJ [Theuns et al., 1986]. More specifically, the increase in solubility could be related to higher concentrations of carbonate in hydroxyapatite, which reduce enamel crys- 
tallinity [Legeros et al., 1967; LeGeros and Tung, 1983]. These variations in the properties of the enamel mineral should be taken into consideration when enamel specimens are used in in vitro experiments.

A great number of in vitro and in situ experiments in dentistry require ground and polished enamel specimens for the most accurate results. Depending on the laboratory procedures for specimen preparation, different amounts of mineralized tissue could be removed from the outer enamel, exposing different depths, which may, in turn, have different mineral compositions and solubilities. It is, therefore, reasonable to assume that different depths of enamel could have different susceptibility to dental erosion. Shellis et al. [2011] have suggested that specimen preparation and polishing procedures should be standardized to ensure the removal of a consistent outer layer of enamel, thus producing specimens with a standardized depth. Two studies [Ganss et al., 2000; Sullivan, 1954 ] suggest that natural enamel surfaces are less susceptible to erosive challenges than ground surfaces in the underlying enamel. This could be related to the acquisition of fluoride by the outermost layer of enamel during enamel maturation [Brudevold et al., 1956; Nakagaki et al., 1987], which consequently becomes more resistant to demineralization [Ganss et al., 2000; Meurman and Frank, 1991]. Calculations from the data of Sullivan [1954] suggest that the less-soluble surface layer is only a few micrometres thick. The response to erosion of polished surfaces of enamel at different depths, which is more relevant to experimental studies, has not been studied.

Additionally, as enamel properties could also vary with tooth origin, tooth type and tooth surfaces, standardization of these factors may also be necessary. In their natural form, different tooth surfaces have been found to have different susceptibilities to erosion [Ganss et al., 2000; Tucker et al., 1998]; in particular labial/buccal surfaces were less susceptible to erosion than lingual/palatal surfaces [Tucker et al., 1998]. The variation in demineralization between different natural surfaces could be due to differences in the extent to which the fluoride-rich layer is lost by wear [Weatherell et al., 1974]. However, after grinding and polishing, no significant differences in the susceptibility of buccal, lingual and proximal surfaces were observed [Ganss et al., 2000].

To the best of our knowledge, the effects of tooth type, tooth surface and enamel depth on initial enamel erosion (softening) are yet to be studied in a systematic experimental model of ground, polished surfaces. Therefore, the aim of this study was to investigate the susceptibility of enamel to an acid demineralization exposure representing initial erosion, analyzing the effect of tooth type (molars or premolars), tooth surface (buccal or lingual) and enamel depths $(100,200,400$ and $600 \mu \mathrm{m})$ on surface microhardness and calcium release.

\section{Materials and Methods}

\section{Enamel Specimen Preparation}

Forty caries-free human teeth (20 molars and 20 premolars) were randomly selected from a pool of extracted teeth stored in $2 \%$ chloramine solution. The teeth were erupted and extracted from patients (below 30 years) by dental practitioners in Switzerland (no water fluoridation, $250 \mathrm{ppm} F$ in table salt). Patients had been informed about the use of their teeth for research purposes and consent was obtained. The premolars and molars were each divided randomly into two groups of 10: experimentals and controls. The crown of each tooth was cut in the vertical mesiodistal plane and the half-crowns individually covered with a layer of nail polish. The buccal and lingual halves of each tooth were both assigned to the same experimental or control group, so that each group contained 10 lingual and 10 buccal specimens of both premolars and molars.

The half-crowns were individually embedded in acrylic resin (Paladur, Heraeus Kulzer GmbH, Hanau, Germany) using two planar parallel molds. The larger mold had a constant thickness of $8 \mathrm{~mm}$, whereas the thickness of the thinner mold varied according to how much enamel was to be removed during grinding. The specimens were serially abraded (LabPol 21, Struers, Ballerup, Denmark) with water-cooled silicon carbide paper discs (from grit $\# 500$ to \#4,000) and polished with diamond paste under constant cooling. The specimens were stored in a mineral solution until the start of the experiment $\left(1.5 \mathrm{mmol} / 1 \mathrm{CaCl}_{2}, 1.0 \mathrm{mmol} / 1 \mathrm{KH}_{2} \mathrm{PO}_{4}, 50\right.$ $\mathrm{mmol} / \mathrm{l} \mathrm{NaCl}, \mathrm{pH}=7.0$ ) [Zero et al., 1990].

\section{Experimental Groups and Experimental Procedure}

The first grinding and polishing procedure removed a $100 \mu \mathrm{m}$ layer of the surface enamel. On the resulting test surfaces, the initial microhardness $\left(\mathrm{SMH}_{0}\right)$ was measured. The experimental specimens, but not the controls, were then exposed to a sequence of three standard erosive challenges, after each of which the loss of surface microhardness $(\triangle \mathrm{SMH})$ and the calcium release were measured. Then the specimens were embedded again, ground and polished to obtain a new, deeper test surface to which these procedures were again applied. Data were obtained in this way for depths of $100,200,400$ and $600 \mu \mathrm{m}$ from the enamel surface.

Surface microhardness (SMH) was measured with a Knoop microhardness tester (UHL VMHT Microhardness Tester, UHL technische Mikroskopie GmbH \& Co., KG, Asslar, Germany), using a load of $10 \mathrm{~g}$ and dwell time of $10 \mathrm{~s}$. For each SMH measurement, six indentations were made on the enamel surface, at $25 \mu \mathrm{m}$ intervals, and used to calculate the mean $\mathrm{SMH}$ for the respective surface.

Three erosive challenges were carried out at each measurement depth on the specimens in the experimental group. One erosive challenge consisted of immersing the specimen for $1 \mathrm{~min}$ in $30 \mathrm{ml}$ of $1 \%$ citric acid $\left(\mathrm{pH}=3.6 ; 25^{\circ} \mathrm{C}\right.$; shaking at $70 \mathrm{rpm}$.), then rinsing 
Table 1. Median (interquartile range) for initial surface microhardness $\left(\mathrm{SMH}_{0}\right)$ values of the different tooth types at each enamel depth

\begin{tabular}{|c|c|c|c|c|}
\hline \multirow{2}{*}{$\begin{array}{l}\text { Enamel depth, } \\
\mu \mathrm{m}\end{array}$} & \multicolumn{2}{|l|}{ Molar } & \multicolumn{2}{|l|}{ Premolar } \\
\hline & buccal & lingual & buccal & lingual \\
\hline 100 & $398(394-406)^{\mathrm{a}}$ & $405(395-414)^{\mathrm{a}}$ & $404(395-415)^{\mathrm{a}}$ & $403(394-410)^{\mathrm{a}}$ \\
\hline 200 & $386(377-397)^{b}$ & $386(379-396)^{b}$ & $385(380-392)^{b}$ & $377(370-386)^{\mathrm{b}}$ \\
\hline 400 & $363(357-372)^{c}$ & $356(349-363)^{c}$ & $356(341-363)^{c}$ & $348(344-359)^{\mathrm{c}}$ \\
\hline 600 & $353(336-364)^{\mathrm{c}}$ & $338(330-351)^{d}$ & $330(320-336)^{d}$ & $327(317-334)^{\mathrm{d}}$ \\
\hline
\end{tabular}

Different superscript letters indicate significant differences $(\mathrm{p}<0.001)$ between depths within the same tooth type and surface.

with deionized water (10 s) and drying with oil-free air (5s). After each erosive challenge, $\mathrm{SMH}$ was measured again. $\mathrm{SMH}$ loss $\left(\Delta \mathrm{SMH}_{\mathrm{i}}\right)$ was calculated using the formula $\Delta \mathrm{SMH}_{\mathrm{i}}=\mathrm{SMH}_{0}-$ $\mathrm{SMH}_{\mathrm{i}}$, where $\mathrm{SMH}_{0}$ is the initial SMH (before any erosive challenge) and $\mathrm{SMH}_{\mathrm{i}}$ is the value after the ith erosive challenge ( $\mathrm{i}=1$, 2 or 3 ).

The calcium released into the citric acid was determined using an atomic adsorption spectrophotometer with acetylene-air flame (A Analyst 400, Perkin Elmer Analytical Instruments, USA). Lanthanum nitrate was added to the standard and test solutions (final concentration $0.5 \% \mathrm{w} / \mathrm{v}$ ) to eliminate interference from phosphate ions.

The surface area of each test surface was measured in all specimens before the erosive challenges. Images of the test surface were obtained using a light microscope (Leica, M420) at $12.5 \times$ magnification, connected to a camera (Leica, DFC495). Using the software program IM500, the contour of exposed enamel was traced and the surface area calculated (in $\mathrm{mm}^{2}$ ). Calcium release ( $\mathrm{nmol}$ calcium/ $\mathrm{mm}^{2}$ enamel) was calculated from the calcium concentrations and the surface areas of the test surfaces.

\section{Statistical Analyses}

The following null hypotheses were tested:

(1) The erosive challenges made on a given enamel layer do not influence $\mathrm{SMH}_{0}$ of subsequent deeper layers;

(2) There is no difference in $\mathrm{SMH}_{0}$ throughout the cyclic treatment between the different enamel depths;

(3) There is no difference in $\triangle \mathrm{SMH}$ throughout the cyclic treatment in relation to tooth type, tooth surface or enamel depth;

(4) There is no difference in calcium release throughout the cyclic treatment in relation to tooth type, tooth surface or enamel depth.

The Wilcoxon rank test was initially used to test the differences in $\mathrm{SMH}_{0}$ between the control and experimental groups (testing null hypothesis 1). Then, a nonparametric ANOVA model (Brunner-Langer F1-LD-F2 model) [Brunner et al., 2002] was used to analyze differences in $\mathrm{SMH}_{0}$ in relation to tooth type and enamel depth (null hypothesis 2). To test null hypotheses 3 and 4, $\Delta \mathrm{SMH}$ and calcium release data were first analyzed with a nonparametric ANOVA for multiple responses. Thereby, three-dimensional response vectors $\triangle \mathrm{SMH}$ and calcium release (one entry for every erosion) were modeled. To do this, the $\triangle \mathrm{SMH}$ and calcium release values after every erosive challenge were used to make a vector (e.g. $\Delta \mathrm{SMH}$-Erosion 1, $\Delta \mathrm{SMH}$-Erosion 2, $\Delta \mathrm{SMH}$-Erosion 3) and later analyzing whether the describing values would have an impact on the whole vector. Subsequently, Brunner-Langer F1-LD-F2 models [Brunner et al., 2002] were again used, considering the tooth as a measuring unit. The statistical models were calculated using the R Project for Statistical Computing (www.r-project.org; Vienna, Austria) version 2.12.1.

The relationships between calcium release and $\triangle \mathrm{SMH}$ were explored using ordinary least-squares regression, using XLStat software, version 7.5 (Addinsoft, Brooklyn, N.Y., USA).

Experimentwise probability for significance $(\alpha)$ was set at 0.05 .

\section{Results}

No significant difference $(\mathrm{p}<0.05)$ was found in $\mathrm{SMH}_{0}$ between the control and experimental groups, thus leading to the acceptance of null hypothesis 1 (erosive challenges made at one depth did not influence measurements at greater depths). It was observed that $\mathrm{SMH}_{0}$ significantly decreased with depth for all tooth surfaces $(\mathrm{p}<$ 0.001 ). On average, total decreases of 11 and $16 \%$ were observed for buccal and lingual surfaces of molars, and 18 and 19\% for buccal and lingual surfaces of premolars, respectively (table 1). These differences led to the rejection of null hypothesis 2 .

The overall multivariate analysis showed that tooth type significantly influenced $\triangle \mathrm{SMH}(\mathrm{p} \leq 0.022)$, where $\triangle \mathrm{SMH}$ was significantly greater in premolars than molars $(\mathrm{p}<0.05)$. Tooth type and enamel depth also showed a significant influence on calcium release $(\mathrm{p}<0.05)$. On the other hand, tooth surface did not significantly influence either $\triangle \mathrm{SMH}(\mathrm{p}=0.801)$ or calcium release $(\mathrm{p}=$ $0.370)$.

The distributions of $\triangle \mathrm{SMH}$ and calcium release for both molars and premolars are shown in figure 1, accord- 


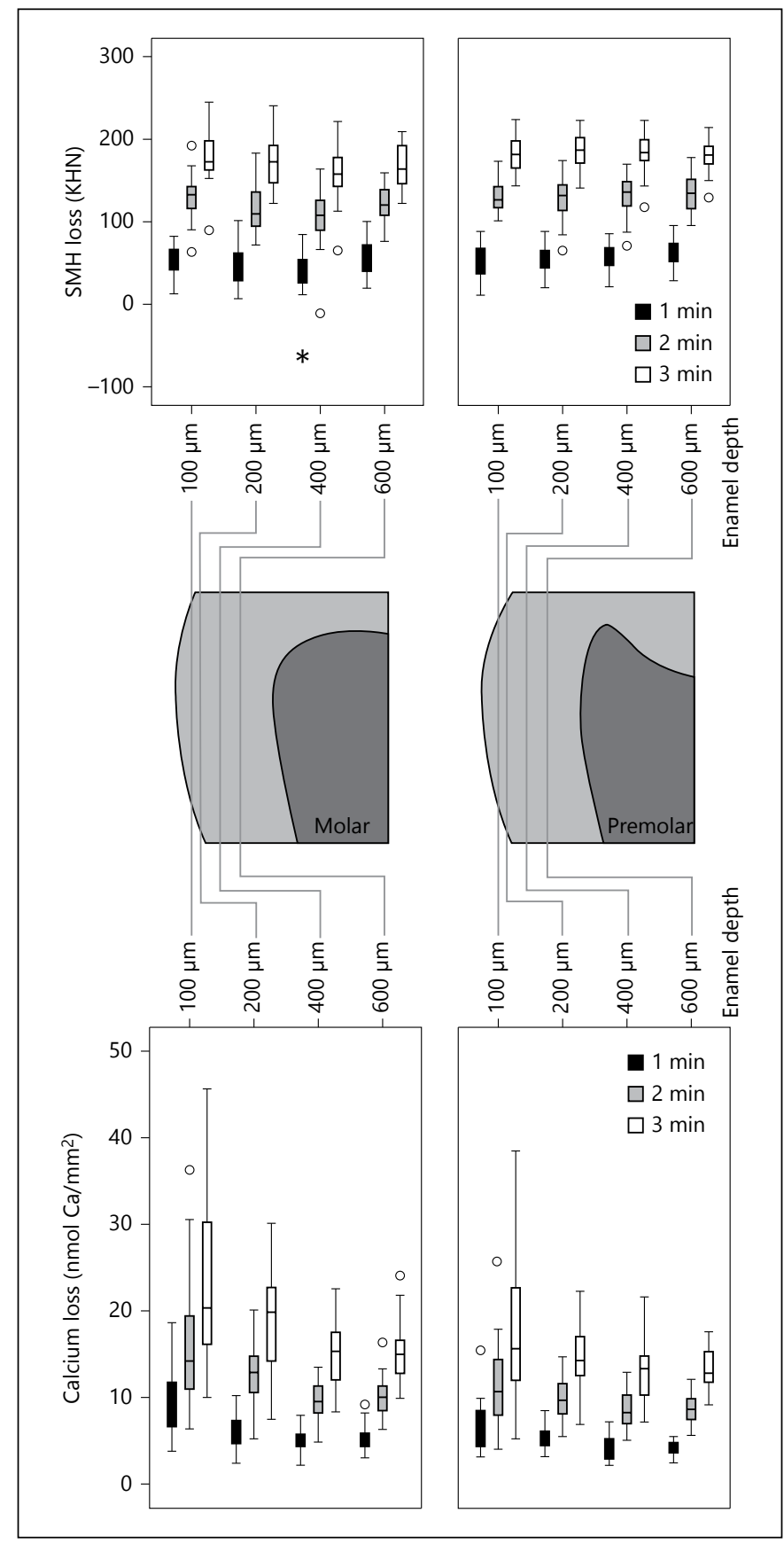

Fig. 1. Box plots showing the distribution of surface microhardness loss $(\triangle \mathrm{SMH})$ and cumulative amount of calcium released to the citric acid after 1, 2 and 3 erosive challenges, according to the tooth type and enamel depth (100, 200, 400 and $600 \mu \mathrm{m})$.

ing to the erosive challenge (1,2 and $3 \mathrm{~min}$ ) and enamel depth. In all depths from both tooth types $\triangle \mathrm{SMH}$ and calcium release increased from erosive challenge 1 to erosive challenge 3 . With regard to $\triangle \mathrm{SMH}$, a significant difference was found between the tooth types in all three

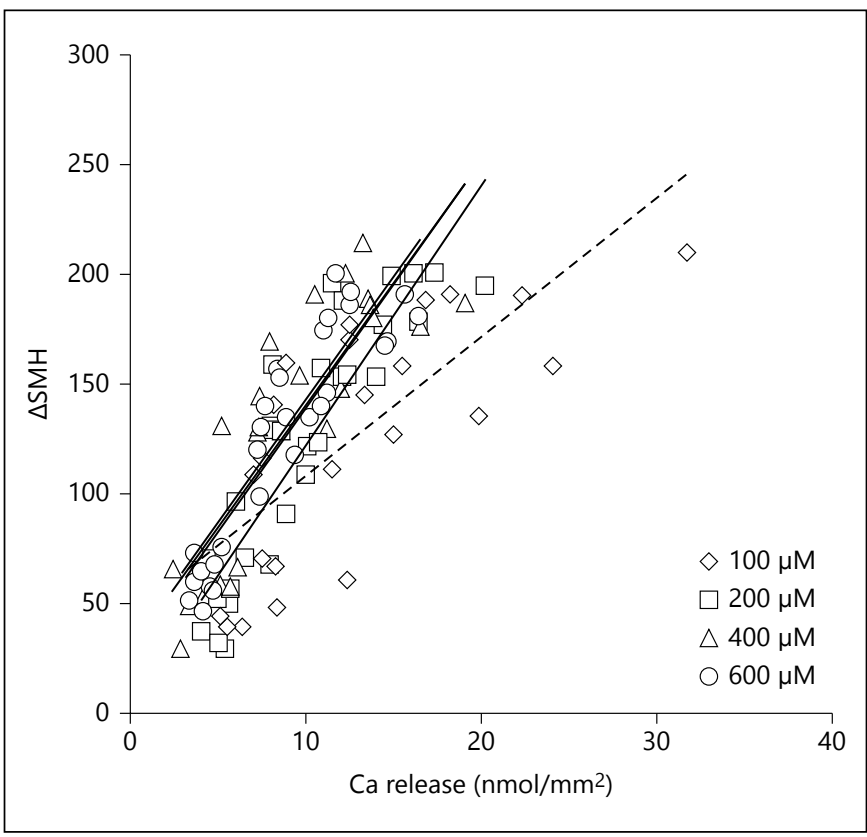

Fig. 2. Scatter plot showing the relationship between $\triangle S M H$ and Ca release for premolars. Dashed line: linear regression for $100 \mu \mathrm{m}$ depth; solid lines: regressions for 200, 400 and $600 \mu \mathrm{m}$ depth.

erosive challenges $(\mathrm{p}=0.023, \mathrm{p}=0.020$ and $\mathrm{p}=0.019$, for 1,2 and 3 challenges, respectively). However, no significant difference in $\triangle \mathrm{SMH}$ was found between the enamel depths ( $p>0.05)$. A significant difference in calcium release was observed between both tooth types in all three erosive challenges $(\mathrm{p}=0.010, \mathrm{p}=0.022$ and $\mathrm{p}=0.050$, for 1,2 and 3 challenges, respectively), with slightly higher values for molars. For 1, 2 and 3 challenges, calcium release decreased with depth (fig. 1) and the differences between enamel depths were statistically significant $(\mathrm{p}<$ $0.001, p=0.028$ and $p<0.001$, for 1,2 and 3 challenges, respectively).

The relationship between calcium release and $\triangle \mathrm{SMH}$ was studied separately for molars and premolars. Duplicate observations on the same tooth were averaged before the analysis. At the level of particular combinations of depth and erosion time, regression slopes were low $(0.03-$ 7.63), as were the values of $\mathrm{r}^{2}(0-0.611)$ (fig. 2); only for 2 of the 24 combinations was the slope significantly different from zero.

Regressions of $\triangle \mathrm{SMH}$ on Ca release were calculated for each depth. For both molars and premolars, the regressions for $100 \mu \mathrm{m}$ showed a lower slope and lower value of $\mathrm{r}^{2}$ (fig. 2; table 2). This was associated with the range of Ca release being $50-100 \%$ greater than for any of the other depths (fig. 2). Regressions for 200-600 $\mu \mathrm{m}$ were 
Table 2. Regressions of $\Delta \mathrm{SMH}$ on calcium release

\begin{tabular}{|c|c|c|c|c|c|c|}
\hline \multirow[t]{2}{*}{ Depth, $\mu \mathrm{m}$} & \multicolumn{3}{|c|}{ Molar } & \multicolumn{3}{|c|}{ Premolar } \\
\hline & $\mathrm{a}$ & $\mathrm{b}$ & $r^{2}$ & a & $\mathrm{b}$ & $r^{2}$ \\
\hline 100 & 59.9 & 3.71 & 0.366 & 45.9 & 6.32 & 0.543 \\
\hline 200 & 12.6 & 7.59 & 0.752 & 4.4 & 11.84 & 0.789 \\
\hline 400 & 4.8 & 9.14 & 0.651 & 29.2 & 11.15 & 0.739 \\
\hline 600 & 27.7 & 8.54 & 0.743 & 23.3 & 11.74 & 0.830 \\
\hline 200-600, combined & 19.6 & 7.89 & 0.686 & 21.9 & 11.26 & 0.763 \\
\hline
\end{tabular}

$\mathrm{a}=$ Intercept $\mathrm{b}=$ slope $\mathrm{r}^{2}=$ coefficient of determination.

very similar (fig. 2) and the regression for the combined data for these depths gave moderately large $\mathrm{r}^{2}$ values (table 2). For all depths, $\triangle \mathrm{SMH}$ increased more rapidly with calcium release in premolars than in molars (table 2 ).

\section{Discussion}

The present study aimed to analyze the effect of tooth type, tooth surface and enamel depth on the loss of surface microhardness $(\triangle \mathrm{SMH})$ and calcium release during the very initial stages of dental erosion. In general, we observed that different types of teeth have a significant influence on the susceptibility of enamel to initial erosive dissolution, but no significant difference was observed between the buccal and lingual surfaces of the same tooth. Also, different enamel depths significantly influenced calcium release.

It is well established that different teeth have different formation periods, different anatomy and different histology. So it not surprising that premolars and molars presented different susceptibility to dental erosion. Likewise, when an individual tooth is formed, amelogenesis occurs from the occlusal/incisal surface toward the cervical region in a process that lasts between 3 and 6 years, depending on the tooth [Reid and Dean, 2006]. So, at any given time during the amelogenesis, the enamel mineral will be formed almost simultaneously on the proximal, buccal and lingual surfaces of the tooth. This implies that, within the same tooth, the buccal and lingual surfaces will probably have very similar enamel composition, which could explain why we observed no significant differences between these surfaces, as observed by Ganss et al. [2000].

The grinding and polishing procedure used in several erosion studies removes the outermost enamel layer, which accounts for the variation between the buccal and lingual natural surfaces [Ganss et al., 2000; Tucker et al., 1998]. Accordingly, this procedure exposes the subsurface enamel that appears to be more homogeneous, albeit more susceptible to dissolution. Although enamel mineral is formed almost simultaneously on different tooth surfaces, it is formed from the DEJ outwards; so different enamel depths can have different mineral compositions.

Initially, the present experiment confirmed that deeper layers of enamel were not affected by previous erosive challenges (e.g. the erosive challenges made on the 100 $\mu \mathrm{m}$ layer did not affect the newly ground enamel at 200 $\mu \mathrm{m}$ depth). This is consistent with the finding by Voronets and Lussi [2010] that after a 3-min erosive challenge with citric acid, a layer of less than $0.5 \mu \mathrm{m}$ of enamel was affected. In the present experiment, we also used a total erosion time of $3 \mathrm{~min}$, so we can speculate that the softened enamel layer on our specimens was also around $0.5 \mu \mathrm{m}$ deep, and the consecutive underlying enamel layers (of at least $100 \mu \mathrm{m}$ apart) were unaffected by the erosive challenges.

Although initial hardness values $\left(\mathrm{SMH}_{0}\right)$ were unaffected by previous acid challenges, they were nevertheless found to decrease with enamel depth, which was also observed by Kodaka et al. [1992]. It is reasonable to suggest that this reflects the gradient of mineral content and density noted in the Introduction, since SMH is correlated with phosphorus and calcium concentrations [Kodaka et al., 1992]. Indeed, preliminary experiments in our laboratory have shown that calcium and phosphate contents tend to decrease when enamel depth increased from 100 $\mu \mathrm{m}$ to $600 \mu \mathrm{m}$ in both premolars and molars.

In this work, we used two techniques to evaluate enamel erosion. Surface microhardness is probably the most long-established method for this purpose, while chemical analysis of calcium release is also a reliable and sensitive method for assessing erosion [Rakhmatullina et al., 2011; Schlueter et al., 2011]. The change in surface microhardness detects the loss of resistance to penetration of an indenter and, when measured in the central part of the test facet, it will reflect surface properties at the depth defined by the preparation procedure. Calcium release, on the other hand, measures loss of enamel due to demineralization over the whole surface of the test facet, which includes enamel from all depths from the surface down to the specified depth. Even though they measure different properties of erosion, both $\triangle \mathrm{SMH}$ and $\mathrm{Ca}$ release increased as the erosion time (i.e. the severity of the erosive challenge) increased. Moreover, there was a fairly strong linear relationship between the two measures, at least for 
depths $\geq 200 \mu \mathrm{m}$. It is, however, notable that the relationship between the two methods, and the strength of the association, were not the same at a depth of $100 \mu \mathrm{m}$ as at greater enamel depths.

As the solubility of enamel mineral increases with depth [Theuns et al., 1986], it might be expected that $\triangle \mathrm{SMH}$ and calcium release would both increase with depth, but $\triangle \mathrm{SMH}$ showed no variation, while calcium release decreased with depth (fig. 1). The first observation is perhaps easier to explain. In the citric acid solution used here, which is completely unsaturated with respect to all fractions of enamel mineral, the rate of dissolution would be at a maximum [Blum and Lasaga, 1987], although the rate would depend on such solution properties as buffering and $\mathrm{pH}$ [Shellis et al., 2013]. In this study the erosive challenge was the same for all test surfaces and, from data on enamel thickness in the mid to occlusal portion of premolar and molar crowns [Shillingburg and Grace, 1973], the test surfaces would be mostly in the outer half of the enamel, where the mineral content decreases by only a few per cent [Wilson and Beynon, 1989]. Both factors would tend to favor a consistent subsurface effect. It is, however, difficult to account for the variation of Ca release with depth, and the weak association with $\triangle \mathrm{SMH}$ at the level of a test facet. It is possible that, when exposed to an unsaturated solution, the rate of dissolution could be influenced by the fraction of the test surface occupied by mineral, that is, by the mineral content by volume, which decreases with depth. However, the observed gradients in mineral content of enamel [Weatherell et al., 1974; Wilson and Beynon, 1989] would not account for the Ca release at $100 \mu \mathrm{m}$ depth being $50-100 \%$ greater than in the deeper enamel. Furthermore, it could be ar- gued that the present results could be interpreted as indicating that calcium analyses has some limitations, mainly due to its high variability, which is affected by changes in enamel depth. However, the statistical analyses take these variations into consideration, and even though we observed a high variability in the calcium results, the differences in calcium release between enamel depths were still significant.

In conclusion, SMH loss and calcium release are different in molars and premolars, and, in both types of teeth, deeper layers of enamel tend to release lower amounts of calcium. So, in practical terms, our results suggest that, when Ca release is used to measure erosion, the depth of the test facet in enamel should be standardized, although this is less important if $\triangle \mathrm{SMH}$ is used.

\section{Acknowledgments}

The authors wish to thank Prof. Dr. R.P. Shellis for his invaluable comments and review of this manuscript. We greatly appreciate the measurements made by Brigitte Megert, Department of Preventive, Restorative and Pediatric Dentistry from the University of Bern, the statistical analyses performed by J. Wandel, L. Martig and Prof. Hüsler, Institute of Mathematical Statistics and Actuarial Science, University of Bern, and the valuable discussion and contribution from Joachim Koeser. We are also grateful to the University of Bern and GABA International AG for supporting this study. Both authors TSC and AL were involved in conceiving and designing the experiments, performing the experiments, data analyses and interpretation and drafting the manuscript.

\section{Disclosure Statement}

The authors declare no conflict of interest in the present study.

\section{References}

Blum AE, Lasaga AC: Monte Carlo simulations of surface reaction rate laws; in Stumm W (ed): Aquatic Surface Chemistry: Chemical Processes at the Particle-Water Interface. New York, Wiley, 1987, pp 255-292.

Brudevold F, Gardner DE, Smith FA: The distribution of fluoride in human enamel. J Dent Res 1956;35:420-429.

Brunner E, Domhof S, Langer F: Nonparametric analysis of longitudinal data in factorial experiments. New York, John Wiley \& Sons, 2002, pp 243-244.

-Daculsi G, Menanteau J, Kerebel LM, Mitre D: Length and shape of enamel crystals. Calcif Tissue Int 1984;36:550-555.

Ganss C, Klimek J, Schwarz N: A comparative profilometric in vitro study of the susceptibil- ity of polished and natural human enamel and dentine surfaces to erosive demineralization. Arch Oral Biol 2000;45:897-902.

Hallsworth AS, Weatherell JA: The microdistribution, uptake and loss of fluoride in human enamel. Caries Res 1969;3:109-118.

Kodaka T, Debari K, Yamada M, Kuroiwa M: Correlation between microhardness and mineral content in sound human enamel (short communication). Caries Res 1992;26:139-141.

Legeros RZ, Trautz OR, Legeros JP, Klein E, Shirra WP: Apatite crystallites: effects of carbonate on morphology. Science 1967;155:14091411.

LeGeros RZ, Tung MS: Chemical stability of carbonate- and fluoride-containing apatites. Caries Res 1983;17:419-429.
Meurman JH, Frank RM: Progression and surface ultrastructure of in vitro caused erosive lesions in human and bovine enamel. Caries Res 1991;25:81-87.

Nakagaki H, Koyama Y, Sakakibara Y, Weatherell JA, Robinson C: Distribution of fluoride across human dental enamel, dentine and cementum. Arch Oral Biol 1987;32:651-654.

Rakhmatullina E, Bossen A, Höschele C, Wang X, Beyeler B, Meier C, Lussi A: Application of the specular and diffuse reflection analysis for in vitro diagnostics of dental erosion: correlation with enamel softening, roughness, and calcium release. J Biomed Opt 2011;16:107002.

Reid DJ, Dean MC: Variation in modern human enamel formation times. J Hum Evol 2006;50: 329-346. 
Robinson C, Weatherell JA, Hallsworth AS: Variatoon in composition of dental enamel within thin ground tooth sections. Caries Res 1971;5: 44-57.

Schlueter N, Hara A, Shellis RP, Ganss C: Methods for the measurement and characterization of erosion in enamel and dentine. Caries Res 2011;45(suppl 1):13-23.

-Shellis RP, Barbour ME, Jesani A, Lussi A: Effects of buffering properties and undissociated acid concentration on dissolution of dental enamel in relation to $\mathrm{pH}$ and acid type. Caries Res 2013;47:601-611.

-Shellis RP, Ganss C, Ren Y, Zero DT, Lussi A: Methodology and models in erosion research: discussion and conclusions. Caries Res 2011; 45(suppl 1):69-77.
Shillingburg HT Jr, Grace CS: Thickness of enamel and dentin. J South Calif Dent Assoc 1973; 41:33-36 passim.

Sullivan HR: The solubility of enamel surfaces. J Dent Res 1954;33:504-510.

Theuns HM, Driessens FC, van Dijk JW, Groeneveld A: Experimental evidence for a gradient in the solubility and in the rate of dissolution of human enamel. Caries Res 1986; 20:24-31.

Tucker K, Adams M, Shaw L, Smith AJ: Human enamel as a substrate for in vitro acid dissolution studies: influence of tooth surface and morphology. Caries Res 1998;32:135-140.

Voronets J, Lussi A: Thickness of softened human enamel removed by toothbrush abrasion: an in vitro study. Clin Oral Investig 2010;14: 251-256.
Weatherell JA, Robinson C, Hallsworth AS: Variations in the chemical composition of human enamel. J Dent Res 1974;53:180-192.

Weatherell JA, Robinson C, Hiller CR: Distribution of carbonate in thin sections of dental enamel. Caries Res 1968;2:1-9.

Wilson PR, Beynon AD: Mineralization differences between human deciduous and permanent enamel measured by quantitative microradiography. Arch Oral Biol 1989;34:8588.

Zero DT, Rahbek I, Fu J, Proskin HM, Featherstone JD: Comparison of the iodide permeability test, the surface microhardness test, and mineral dissolution of bovine enamel following acid challenge. Caries Res 1990;24:181188. 